\title{
Comportamento térmico de compósitos de poliestireno reciclado reforçado com celulose de bagaço de cana
}

\section{Thermal properties of recycled polystyrene composite reinforced with cellulose from sugarcane bagasse}

\author{
Luiz Carlos Correia de Jesus ${ }^{1}$, Sandra Maria da Luz ${ }^{2}$, \\ Rosineide Miranda Leão ${ }^{2,3}$, Ademir José Zattera ${ }^{4}$, \\ Sandro Campos Amico ${ }^{5}$
}

\footnotetext{
${ }^{1}$ Departamento de Engenharia Mecânica, Faculdade de Tecnologia - Universidade de Brasília, CEP: 70910-900, Brasília, Distrito Federal, Brasil.

${ }^{2}$ Faculdade do Gama - Universidade de Brasília, CEP: 72444-240, Brasília, Distrito Federal, Brasil.

${ }^{3}$ Faculdades Integradas da União Educacional do Planalto Central, CEP: 72460-000, Brasília, Distrito Federal, Brasil.

${ }^{4}$ Centro de Ciências Exatas e Tecnologia, Universidade de Caxias do Sul, CEP 95070-560, Caxias do Sul, Rio Grande do Sul, Brasil.

${ }^{5}$ Laboratório de Materiais Poliméricos, Universidade Federal do Rio Grande do Sul, CEP 91501-970, Porto Alegre, Rio Grande do Sul, Brasil.

e-mail: luizquimica@gmail.com
}

\begin{abstract}
RESUMO
O poliestireno expandido (EPS) é um polímero reciclável amplamente utilizado na fabricação de embalagens para isolamento acústico, proteção de bens de consumo duráveis e na indústria da construção civil. O PS é facilmente reciclável com o aumento da temperatura, podendo dar origem a novos materiais. Entretanto suas propriedades térmicas podem ser afetadas, principalmente se acrescidos de fibras naturais. Diante desse contexto, esse trabalho tem como objetivo estudar as propriedades térmicas dos compósitos de poliestireno reciclado reforçados com fibra de celulose do bagaço de cana-de- açúcar. Os compósitos de PS reciclados contendo 10 e $20 \%(\mathrm{~m} / \mathrm{m})$ de celulose de bagaço foram obtidos por extrusão e caracterizados por análise térmica: Análise Termogravimétrica (TGA), Calorimetria Exploratória Diferencial (DSC), Análise DinâmicoMecânica (DMA) e Temperatura de Deflexão Térmica (HDT). Os resultados mostraram que as fibras ricas em lignina residual atuaram como reforço melhorando a rigidez do material com a adição das fibras, bem como promoveram o aumento da temperatura de deflexão térmica. Já a estabilidade térmica dos compósitos é intermediária entre a fibra e matriz, diminuindo com o aumento do teor de fibras. Portanto, conclui-se que a utilização de EPS como matriz na obtenção de compósitos reforçados com fibras naturais é viável e sugere o uso deste resíduo como uma excelente alternativa para o setor de reciclagem.
\end{abstract}

Palavras-chave: poliestireno, celulose, lignina e propriedades térmicas.

\begin{abstract}
Expanded polystyrene (EPS) is a recyclable polymer widely used in the manufacture of packaging for acoustic insulation, protection of durable consumer goods and in the construction industry. The PS is easily recyclable with increasing temperature, giving new materials. However, thermal properties can be affected, mainly if added of natural fibers. In this context, this work objective to study the thermal properties of recycled polystyrene composites reinforced with cellulose fibers from sugarcane bagasse. The recycled composites of PS reinforced 10 and $20 \mathrm{wt} \%$ cellulose bagasse were obtained by extrusion, and characterized by thermal analysis thermogravimetric analysis (TGA), differential scanning calorimetry (DSC), dynamic mechanical analysis (DMA) and heat deflection temperature (HDT). The results showed that the fibers rich in residual lignin act as reinforcement improving the stiffness of the material with the addition of the fibers, as well as promoted the increase of the heat deflection temperature for the composites. The thermal stability of the composites is intermediate between the fiber and matrix, decreasing with the increase of fibers content.
\end{abstract}


Therefore, it is concluded that the use of EPS as a matrix in the obtainment composites reinforced with natural fibers is viable and suggest the use of this residue as an excellent alternative for the recycling industry.

Keywords: polystyrene, cellulose, lignin and thermal properties.

\section{INTRODUÇÃO}

O interesse no uso de fibras naturais como reforço de materiais compósitos está em constante crescimento, principalmente por causa das múltiplas vantagens associadas a este material natural e renovável [1,2]. Dentre as vantagens destacam-se: 1) o tipo de fonte renovável e sua disponibilidade; 2) são menos abrasivas que as fibras sintéticas, resultando em um menor desgaste dos equipamentos envolvidos no seu processamento; e 3) são materiais biodegradáveis. Diversos setores têm buscado alternativas no sentido de diminuir os impactos ambientais decorrentes dos processos produtivos industriais, bem como do uso dos produtos poliméricos e seu descarte. Atualmente, leis governamentais sobre sequestro de carbono e diminuição do impacto do aquecimento global tem estimulado a reciclagem dos materiais poliméricos, bem como o aumento na utilização de compósitos com fibras naturais na indústria [3]. Apesar do módulo de elasticidade das fibras naturais serem menores que as fibras de vidro, este material oferece algumas vantagens em relação às fibras sintéticas, como baixa densidade, biodegradabilidade e baixa abrasividade, garantindo uma maior facilidade no processamento $[1,2]$.

Muitas fibras naturais têm sido utilizadas como reforço em polímeros, tais como a fibra de coco, sisal, bagaço de cana-de-açúcar, cânhamo e algodão [4]. Dentre elas, o bagaço foi escolhido como objeto de estudo neste trabalho por ser um resíduo agroindustrial disponível em grandes quantidades no Brasil. A fibra de bagaço é derivada da moagem da cana-de-açúcar que é o maior subproduto da indústria sucro-alcooleira. Estima-se que cerca de 654 milhões de toneladas de bagaço foram gerados no ano de 2016, aproximadamente $320 \mathrm{~kg}$ por tonelada de cana moída [4]. Esses resíduos agroindustriais são utilizados na própria indústria de álcool e açúcar para a geração energética, no entanto, estes podem ser utilizado em outras aplicações, como por exemplo reforço em materiais compósitos [5].

As fibras naturais são constituídas por diversos componentes, sendo os principais: celulose, hemicelulose e lignina. A unidade repetitiva da celulose é composta por duas moléculas de glicose eterificadas por ligações $\beta-1,4$-glicosídicas. Esta unidade repetitiva, conhecida como celobiose, contém seis grupos hidroxila que estabelecem interações do tipo ligações de hidrogênio intra e intermoleculares. Devido às ligações de hidrogênio, a celulose apresenta uma forte tendência em formar cristais [6,5]. Já a lignina é um material apolar de caráter aromático, não cristalino de grande abundância natural, com uma estrutura altamente ramificada, podendo ser classificada como um polifenol, o qual é constituído por um arranjo irregular de várias unidades de fenilpropano que pode conter grupamentos hidroxila e metoxila como substituintes no grupo fenil. Esta resina hidrofóbica atua como um cimento entre as fibrilas e como um agente enrijecedor no interior das fibras [7]. A força de adesão entre as fibras de celulose e a lignina é estendida pela existência de ligações covalentes entre as cadeias de lignina e os constituintes da celulose e da hemicelulose [8].

Quando se faz a polpação do bagaço, ou seja, o tratamento alcalino, as estruturas lignocelulósicas se rompem, solubilizando a hemicelulose e a lignina por hidrólise de ésteres, ocorrendo assim a extração da celulose, aumentando seu grau de cristalinidade e suas propriedades mecânicas [4,7].

O Brasil e o mundo geram uma grande quantidade de resíduos de polímero entre eles o poliestireno expandido (EPS). Apesar da baixa densidade, o EPS ocupa grande volume, o que onera o transporte e, portanto, sua reciclagem. Segundo o site "Portal da Construção", a produção mundial de EPS no ano de 2016 foi de cerca de 5 milhões de toneladas/ano, destaque para a Ásia, com consumo de 2 milhões, Europa, um milhão e os Estados Unidos, com 700 mil toneladas. O Brasil representa apenas 1\% do mercado global e tem grande potencial de expansão em segmentos como construção civil e setores de embalagens e automotivo, sendo que mais de 75 mil toneladas não foram reciclados [9].

O setor da construção civil é o maior consumidor de EPS. No ano de 2016 foram consumidos $40 \%$ da produção brasileira somente nesta área. As aplicações são inúmeras, como em lajes, isolamento térmicos e acústicos, concreto leve, pontes, ferrovias, dentre outras. Este material tem ciclos de vida curtos em comparação com os produtos feitos de poliestireno e outros polímeros. Como as poliolefinas pós-consumo representam uma das maiores categorias de resíduos, a reciclagem destes materiais e uso na produção de compósitos podem apresentar relevância econômica e ambiental [8]. Por essas razões, o poliestireno expandido será utilizado como matriz para produção de compósitos neste trabalho, servindo para envolver fibras celulósicas de bagaço-de-cana.

Em compósitos, a adesão entre a fibra e a matriz pode advir pelo encaixe mecânico das cadeias da matriz polimérica devido à rugosidade existente na superfície das fibras, por atração eletrostática, orças de Van 
der Waals, interações não covalentes ou formação de ligações químicas mais fortes [10, 11]. Uma forte ligação entre interface fibra/ matriz é importante para uma eficiente transferência de carga aplicada sobre a matriz e as fibras, acarretando um aumento da resistência do material. As fibras são responsáveis por suportarem a maior parte da carga aplicada, sendo mais resistentes que a matriz [12]. Entretanto, para que exista uma boa interação na interface fibra/ matriz são necessários grupos funcionais atuando na região da interface, ou seja, sítios ativos de ácido-base de Lewis ou interações intermoleculares [13].

Para melhorar a adesão entre fibra/ matriz, na literatura são encontradas várias alternativas, destacando o uso de copolímeros como anidrido maléico que é adicionado na etapa de processamento dos compósitos [14]. As fibras celulósicas extraídas do bagaço são ricas em lignina residual depositadas sobre as fibras, que podem ser removidas por sequências de branqueamento [15]. Porém, se o branqueamento não for aplicado, a lignina residual poderá agir como compatibilizante devido as suas características hidrofóbicas ricas em anéis aromáticos, podendo ser compatível com o poliestireno da matriz polimérica, que também apresenta anéis aromáticos em sua estrutura [14]. Como pode ser observado na representação da Figura 1, na interface entre a fibra de celulose e a matriz do poliestireno pode ocorrer interações não covalentes entre os elementos constituintes do reforço e a lignina, e por outro lado, a formação de entrelaçamento entre as cadeias poliméricas da matriz do poliestireno e a lignina [16].

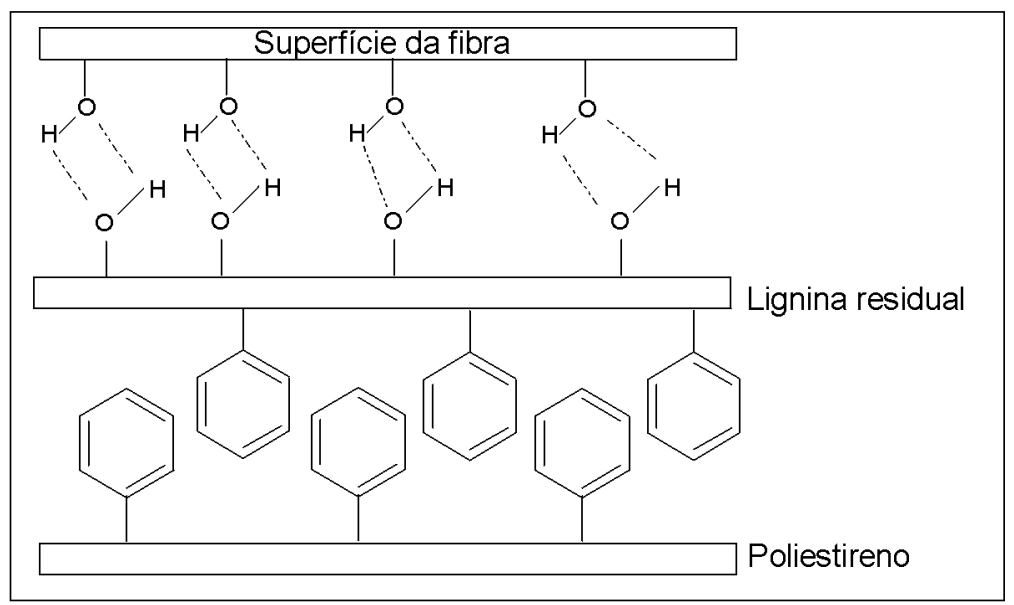

Figura 1: Proposta de interação interfacial entre a fibra celulósica e a matriz de PS, destacando os anéis aromáticos da lignina depositada sobre as fibras e do PS.

Essas interações não covalentes, também chamadas de interações $T$-stacking, juntamente com a ligação de hidrogênio, tem papel importante na determinação de estruturas e propriedades de sistemas moleculares na biologia, na química e na ciência dos materiais [17]. As interações entre grupamentos aromáticos estão entre as mais importantes e menos compreendidas das interações não covalentes, sendo consideradas relevantes em sistemas biológicos, materiais e outros. Pesquisas tem mostrado que as forças não-covalentes são mais fracas que as ligações de hidrogênio convencionais, mas também desempenham um papel importante em processos de auto-organização ou reconhecimento molecular na Química, na Bioquímica ou ainda nas ciências dos materiais [18].

Existem duas situações-limite no que se refere ao arranjo dos anéis aromáticos: um paralelo (face-toface ou empilhamento $\pi \cdots \pi$ ) e o outro perpendicular (edge-to-face ou conformação-T). Embora o termo "empilhamento $\pi \cdots \pi$ " seja algumas vezes indiscriminadamente utilizado, é mais apropriado descrever como interação $\mathrm{C}-\mathrm{H}^{\cdots} \cdots \pi$ (edge-to-face) quando os planos dos anéis aromáticos se encontrarem orientados em um ângulo próximo de $90^{\circ}$ na molécula. Por outro lado, para que haja um empilhamento $\pi \cdots \pi$, não é necessária a ocorrência de um alinhamento facial perfeito dos anéis aromáticos, podendo haver certo deslizamento de um anel com relação ao outro, que é, na verdade, observado na grande maioria dos casos. Vale ressaltar, que nesse empilhamento de grupos aromáticos, à distância interplanar varia de 3,3-3,8 $\mathrm{A}$. Na realidade, as forças intermoleculares que atuam entre os anéis aromáticos e que são responsáveis pela estabilização do empilhamento $\pi \cdots \pi$ - consistem em atrações do tipo Van der Waals de caráter dipolo-dipolo $[17,18]$.

Desta forma, o principal objetivo deste trabalho é obter e caracterizar termicamente os compósitos de poliestireno expandido reforçado com celulose de bagaço de cana-de-açúcar. Além de avaliar o efeito da lignina como agente compatibilizante. 


\section{MATERIAIS E MÉTODOS}

\subsection{Obtenção das Fibras Celulósicas de Bagaço de Cana}

O bagaço de cana-de-açúcar utilizado neste artigo foi gentilmente fornecido pela Edras Ecossistemas possuindo comprimento de 13 a $15 \mathrm{~mm}$. As fibras de bagaço da cana-de-açúcar foram adicionadas em uma solução de $6,25 \mathrm{~mol} / \mathrm{L}$ de $\mathrm{NaOH}$ e 7 x $10^{-3} \mathrm{~mol} / \mathrm{L}$ de antroquinona, obedecendo à relação licor de $6: 1(\mathrm{~m} / \mathrm{v})$. O processo de polpação foi realizado em um reator de aço inoxidável de capacidade de $200 \mathrm{~mL}$ a $80^{\circ} \mathrm{C}$ por 210 minutos. As polpas obtidas foram lavadas com água destilada até atingir o $\mathrm{pH}$ igual a $7 \mathrm{e}$ secas a temperatura de $30^{\circ} \mathrm{C}$.

\subsection{Preparação dos Materiais Compósitos}

O poliestireno expandido foi comprimido a temperatura de $130^{\circ} \mathrm{C}$, e pressão de 8 toneladas por 3 min utilizando uma prensa hidráulica térmica (marca Wabash Hydraulic Press, modelo $12-12$ - 2TWC). Este processo visou o aumento da densidade, e o material obtido foi denominado PS reciclado. O polímero e as fibras de celulose foram submetidos a uma pré-mistura em extrusora mono-rosca (marca SEIBT, modelo ES 35FR). A composição dos compósitos foi fixada em 10 e $20 \%(\mathrm{~m} / \mathrm{m})$ em relação à matriz polimérica. Os compósitos produzidos foram triturados em moinho de facas (marca Primotécnica, modelo 1001). O material triturado, foi novamente extrudado em extrusora dupla-rosca (marca MH Equipamentos modelo COR 20-32-LAB). A extrusora operou com oito zonas de aquecimento variando de $102^{\circ} \mathrm{C}$ a $183^{\circ} \mathrm{C}$, com rotação da rosca de 200 $\mathrm{rpm}$. Os materiais extrudados foram granulados e secos em estufa a $80^{\circ} \mathrm{C}$ por $180 \mathrm{~min}$. Depois foram injetados em uma injetora (marca Himaco, modelo LHS 150-80) com perfis de temperatura de $140^{\circ} \mathrm{C}, 160^{\circ} \mathrm{C}$ e $180^{\circ} \mathrm{C}$, velocidade de rotação da rosca de $100 \mathrm{rpm}$ e a temperatura do molde de $30^{\circ} \mathrm{C}$.

\subsection{Análise Termogravimétrica (TGA/ DTG) e Calorimetria Exploratória Diferencial (DSC)}

As análises de TGA e DSC foram realizadas em um analisador térmico simultâneo TG-DSC da TA Instruments, modelo SDT Q600. As análises foram feitas em cadinho de alumina com cerca de $10 \mathrm{mg}$ de amostra em uma faixa de temperatura de 30 a $500^{\circ} \mathrm{C}$ sob atmosfera de $\mathrm{N}_{2}$ (fluxo de $100 \mathrm{~mL} \cdot \mathrm{min}^{-1}$ ) e razão de aquecimento de $10^{\circ} \mathrm{C} \cdot \mathrm{min}^{-1}$.

\subsection{Análise Termo-Dinâmico-Mecânica (DMA)}

Corpos de prova nas dimensões de 50 x 13 × 3,5 mm foram analisados em reômetro oscilatório (Anton Paar Physica MCR 101), operando em modo de flexão, partindo de $23^{\circ} \mathrm{C}$ até $130^{\circ} \mathrm{C}$ com taxa de aquecimento de $3^{\circ} \mathrm{C}$. $\min ^{-1}$, na frequência de $1 \mathrm{~Hz}$.

\subsection{Temperatura de Deflexão Térmica (HDT)}

A análise foi realizada em um equipamento CEAST, modelo HDT/ 6 VICAT. A taxa de aquecimento utilizada foi de $120^{\circ} \mathrm{C} . \mathrm{h}^{-1} \mathrm{e}$ a carga aplicada de $1,82 \mathrm{MPa}$. O corpo de prova durante o ensaio suportou uma carga, transferindo a tensão aplicada ao material que foi submerso em um banho térmico em óleo de silicone. No ensaio, o material sofreu um deslocamento vertical igual a $0,25 \mathrm{~mm}$.

\section{RESULTADOS E DISCUSSÃO}

\subsection{Obtenção das fibras de celulose}

Para a obtenção das fibras de celulose de bagaço de cana-de-açúcar, foi aplicado o processo de polpação com solução de hidróxido de sódio $(\mathrm{NaOH})$ e antraquinona $(\mathrm{AQ})$ a fim de extrair as fibras de celulose do bagaço e separá-la dos demais componentes (hemicelulose e lignina), ou seja, resultando em um produto com alto teor de celulose e baixa quantidade de lignina. O rendimento das polpações foi de $37 \%$, mostrando que houve uma degradação intensa de todos os componentes devido à alta concentração álcali e temperatura elevada. $\mathrm{O}$ componente mais abundante das fibras celulósicas obtidas foi a celulose com cerca de $83 \%(\mathrm{~m} / \mathrm{m})$. O processo de polpação $\mathrm{NaOH} / \mathrm{AQ}$ degradou preferencialmente a lignina e a hemicelulose, preservando a celulose. Embora, tenha sido observado um baixo rendimento na polpação, a ausência de AQ na polpação poderia ter acarretado em um pior rendimento. CARASCHI et al., [15] demonstraram que o uso de antraquinona no processo de polpação promoveu ganhos no rendimento. Com relação às características das polpas celulósicas, a presença de antraquinona promoveu uma maior deslignificação, resultando em uma polpa com menor teor de lignina, o que possibilitou também o aumento no teor de celulose. 
É importante observar que a quantidade de lignina solúvel $(5,7 \% \mathrm{~m} / \mathrm{m})$ em ácido sulfúrico foi maior que a lignina insolúvel $(2,7 \% \mathrm{~m} / \mathrm{m})$, demonstrando que o processo de polpação foi drástico degradando a macroestrutura da lignina, resultando em compostos de baixa massa molar [19]. A lignina e uma parcela da celulose tem característica amorfa, o que pode influenciar nas propriedades térmicas e dinâmico-mecânicas [7]. Neste trabalho, no entanto a celulose utilizada não é altamente pura, apresentando aspecto bastante fibroso e mantendo a coloração marrom típica de materiais lignocelulósicos (Figura 2).
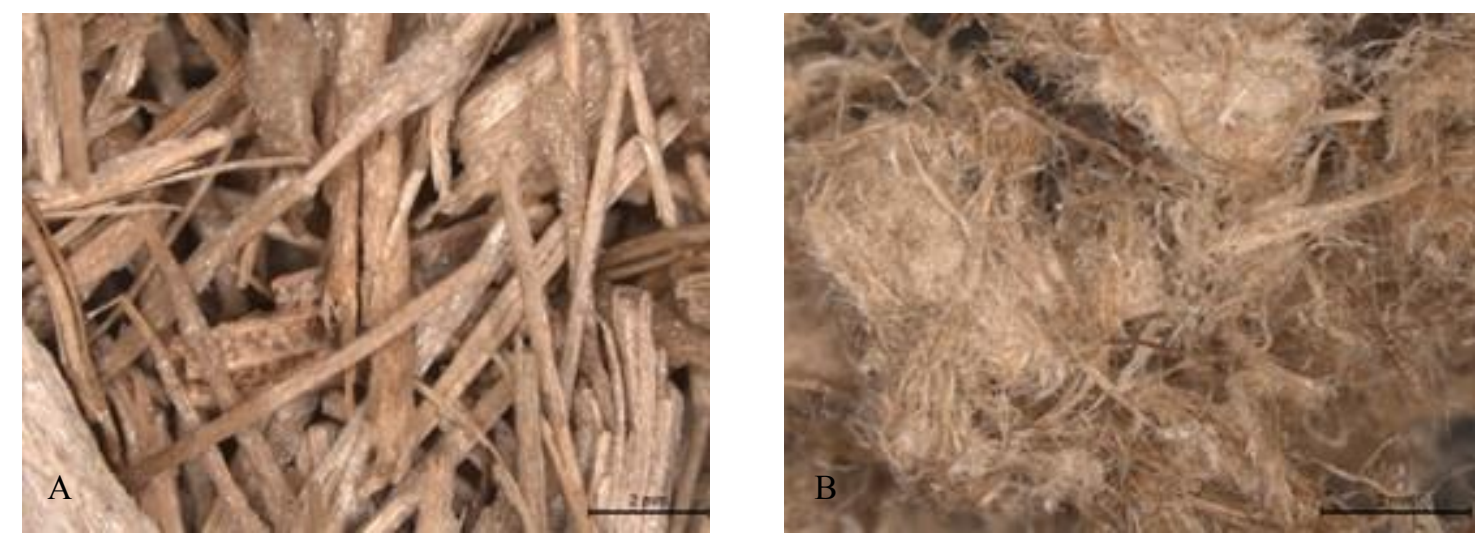

Figura 2: A) fibras in natura de bagaço; B) fibras celulósicas após polpação $\mathrm{NaOH} / \mathrm{AQ}$.

O tipo de processamento pode influenciar as propriedades dos compósitos, alterando as propriedades térmicas e dinâmico-mecânicas. O processo de incorporação de reforço em matriz polimérica é realizado com as fibras dispersas no polímero tornando assim um material isotrópico. É necessário ajustar os parâmetros de processamento de tal forma que não ocorra redução do comprimento da fibra, degradação do filamento, ou mesmo segregação durante a extrusão [21].

\subsection{Comportamento térmico da celulose e dos compósitos}

\subsubsection{Análise termogravimétrica}

O comportamento térmico do PS reciclado (material de poliestireno expandido pós-consumo prensado a quente), da celulose, bem como dos compósitos foi avaliado. As Figuras 3A e 3B mostram que a estabilidade térmica dos materiais foi de cerca de $270^{\circ} \mathrm{C}$ para os compósitos, $230^{\circ} \mathrm{C}$ para a celulose e $350^{\circ} \mathrm{C}$ para o PS reciclado. Desta forma, a estabilidade térmica dos compósitos foi intermediária entre a fibra e a matriz polimérica reciclada. Observa-se também que a perda de massa nos compósitos é mais pronunciada com o aumento da adição de fibras.

A decomposição da celulose e dos compósitos foi caracterizada por dois picos distintos. Para a celulose, a primeira perda de massa ocorreu antes $\operatorname{dos} 100^{\circ} \mathrm{C}$ que pode ser atribuída a perda de umidade da poliose e seus componentes (xilose, manose, glucose e outros) e substâncias voláteis presentes nas fibras [21,22]. A segunda perda de massa apresentou picos na faixa entre 210 e $360^{\circ} \mathrm{C}$, que estar relacionada com a degradação da hemicelulose, celulose e a degradação lenta da lignina. Em temperaturas abaixo de $230^{\circ} \mathrm{C}$ prevalece a decomposição da hemicelulose, e entre 230 e $260^{\circ} \mathrm{C}$ tanto a celulose quanto a hemicelulose sofrem degradação térmica, predominando, acima de $290^{\circ} \mathrm{C}$, a decomposição de celulose [21,22]. A lignina se apresenta como componente mais hidrofóbico da madeira, atuando como material adesivo entre as fibras além de conferir dureza e rigidez à parede celular, sendo o último componente a se degradar [22]. A degradação térmica para $\mathrm{PS}$ reciclado ficou na faixa de $410^{\circ} \mathrm{C}$. Esta degradação é atribuída à quebra de ligações em carbono saturados e insaturados no poliestireno [21].

Verifica-se que a perda de massa é mais acentuada conforme aumenta a adição de fibra celulósica ainda com lignina, lembrando que a lignina pode atuar como agente compatilizante dos compósitos produzidos. Segundo BORSOI et al. [22] uma possível explicação para esse comportamento é que os compósitos compatibilizados apresentam maior interação interfacial, devido interações não covalentes entre os grupos fenílicos do poliestireno e a lignina residual da fibra celulósica, presentes na superfície da fibra. Esse efeito promove uma maior interação entre os processos de degradação dos dois componentes, ou seja, a degradação de um componente pode acelerar a degradação do outro. 

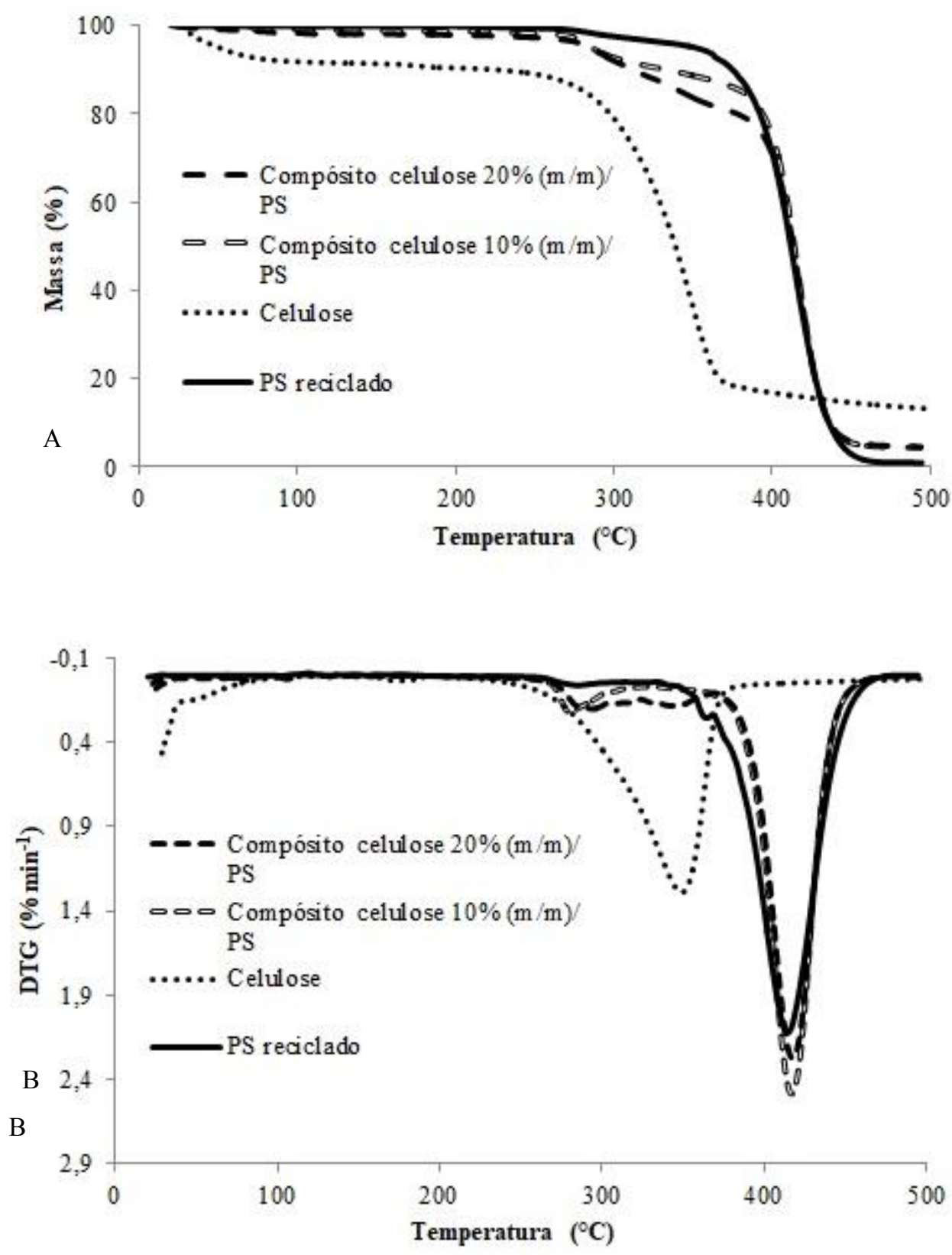

Figura 3: Curvas do PS reciclado, da celulose, do bagaço de cana-de-açúcar e dos compósitos (A); e curvas de DTG do $\mathrm{PS}$ reciclado, da celulose, do bagaço de cana-de-açúcar e dos compósitos (B).

\subsubsection{Calorimetria exploratória diferencial}

As análises térmicas por DSC do PS reciclado, da celulose e dos compósitos estão mostradas na Figura 4. As curvas de DSC do PS reciclado e dos compósitos apresentaram um único evento endotérmico na temperatura de $420^{\circ} \mathrm{C}$, característico da decomposição destes materiais. O principal componente volátil produzido a partir da degradação térmica do poliestireno sob atmosfera inerte é o monômero de estireno [22]. Outros produtos tais como o tolueno, etilbenzeno, benzeno também podem ser identificados como produtos da degradação do poliestireno [22].

Para a celulose foi observado dois picos endotérmicos, o primeiro em $60{ }^{\circ} \mathrm{C}$, atribuído ao calor de vaporização da água e o segundo à degradação da celulose, que ocorreu entre 360 e $470^{\circ} \mathrm{C}$, que pode estarrelacionado à decomposição das polioses e celuloses, corroborando com a perda de massa nesta mesma faixa observada na análise termogravimétrica. A degradação térmica da celulose, observada nas curvas TG, leva a despolimerização e a formação de 1,6 anidroglucose [24]. Este pico pode corresponder à ruptura de ligações hidrogênio inter e intramoleculares, provavelmente envolvendo a estrutura celulósica ou, ainda, ser consequente de acomodações que envolvem as regiões cristalinas da celulose e que provocam alterações no tipo de rede cristalina. Na Figura 4 observa-se que a adição da celulose + lignina residual apresentou um significati- 
vo aumento da entalpia envolvida na degradação. As curvas DSC também podem apresentar informações relacionadas a fusão do material, entretanto, pelo PS ser amorfo, este pico não é observado.

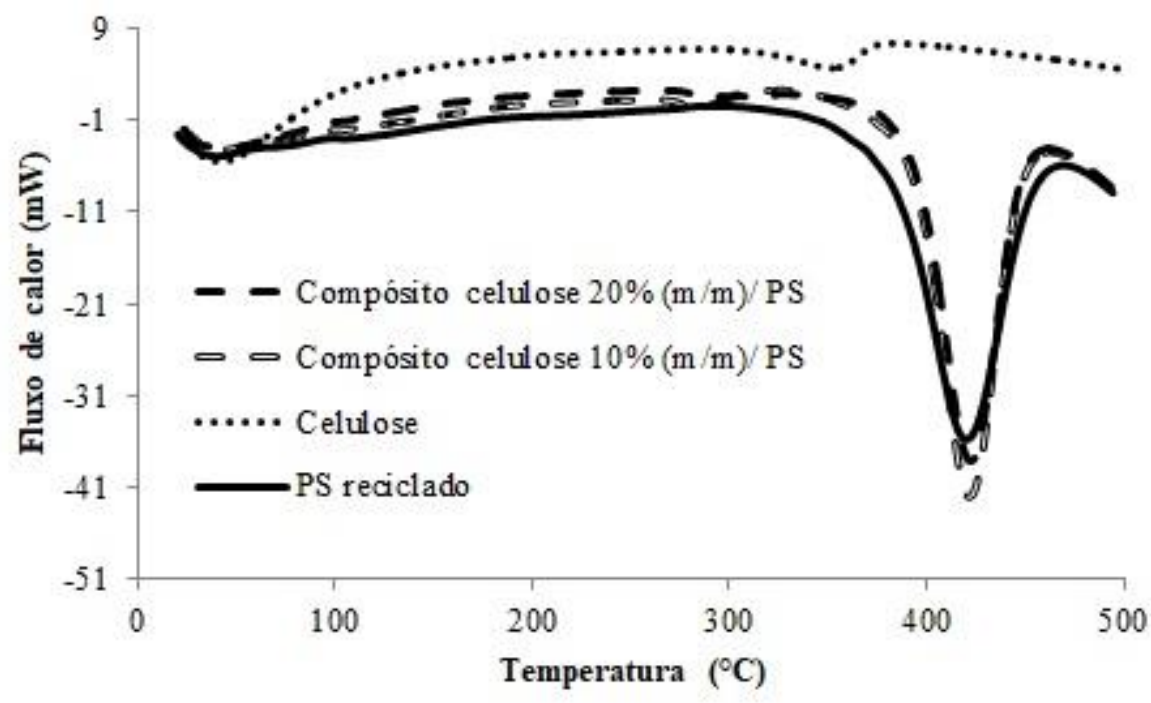

Figura 4: Curvas de DSC para os compósitos em comparação ao PS reciclado e a celulose.

\subsubsection{Análise dinâmica mecânica (DMA)}

Os ensaios de DMA foram realizados para o PS reciclado e os compósitos a fim de verificar o comportamento viscoelástico relacionados ao módulo de armazenamento, módulo de perda e tan $\delta$. Nas Figuras $5 \mathrm{~A}$ e 5B observaram-se um aumento no módulo de armazenamento (E') com a adição da fibra de celulose + lignina residual. Este comportamento pode estar associado ao aumento da restrição molecular imposta pela adição da fibra de celulose sobre a matriz polimérica e ao efeito compatibilizante entre a lignina e a matriz de poliestireno. Os compósitos 20\% celulose (m/m)/ PS apresentaram um E' (pico) de 3,2 GPa, já os compósitos 20\% celulose $(\mathrm{m} / \mathrm{m}) /$ PS apresentaram E' (pico) de 2,9 GPa, ambos são superiores ao módulo do PS reciclado que foi de 2,2 $\mathrm{GPa}$.

A Tabela 1 faz uma comparação dos módulos dinâmicos e o tan $\delta$ entre o PS reciclado e os compósitos. Os módulos E' e E" e tan $\delta$ indicam as mudanças de conformação dos segmentos de cadeia do material polimérico. Portanto estão relacionados diretamente a estrutura, massa molecular e composição. Desta maneira, tudo o que restringe a movimentação dos segmentos de cadeia aumenta E' e diminui tan $\delta$ e E" [28]. No caso dos compósitos reforçados com as fibras de celulose + lignina, esses demonstraram maior módulo de elasticidade devido à adição das fibras na matriz e a boa interação da lignina e a matriz polimérica do poliestireno. Observou-se que o módulo de armazenamento aumenta 32\% e 46\%, respectivamente, para os compósitos com $10 \%$ e $20 \%$ de celulose em comparação com PS reciclado. Com a adição da fibra na matriz de poliestireno e efeito compatibilizante da lignina, o módulo aumentou 30\% para os compósitos, isso comprova que a fibra auxiliou no aumento da rigidez do material. 


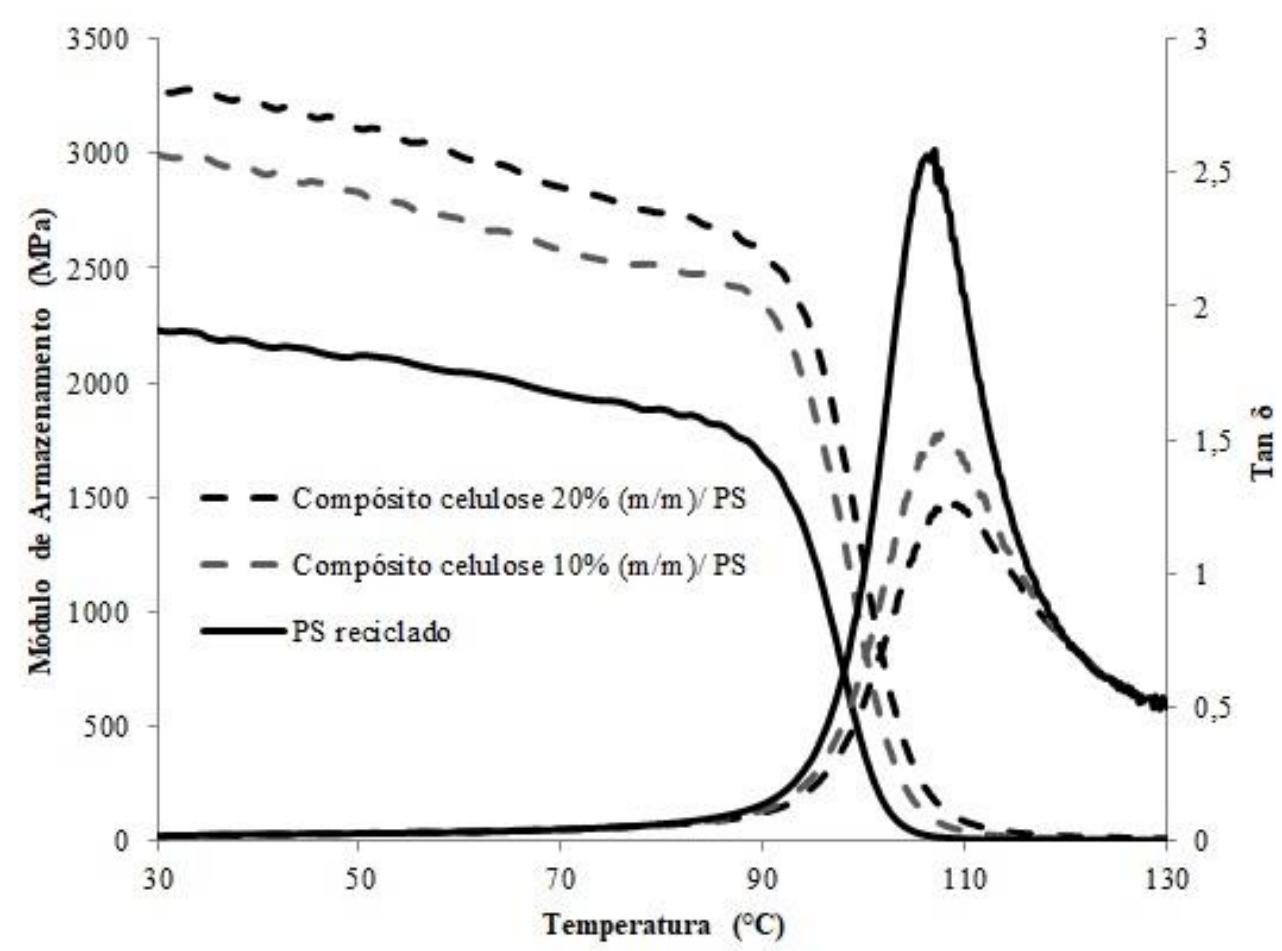

Figura 5: Módulo de armazenamento (E') e Tan $\delta$ para o para o PS reciclado e os compósitos.

A variação de $\tan \delta$ em função da temperatura para o PS reciclado e os compósitos é observada na Figura 5. Para os compósitos analisados, foi observada uma redução no grau de amortecimento em relação ao PS reciclado. Segundo CANEVAROLO Jr. [25], com uma maior interação entre a fibra e a matriz ocorrem restrições ao movimento das cadeias carbônicas encontradas na interface da fibra ocasionando uma um decréscimo do grau de amortecimento com pode ser observado nos valores dos picos de tan $\delta$ que são dados pela Tabela 1. Verificou-se que com a adição da fibra de celulose/ lignina ocorre à redução da altura do pico $\tan \delta$ de 1,48 para os compósitos $10 \%$ celulose $(\mathrm{m} / \mathrm{m}) /$ PS para 1,18 para os compósitos $20 \%$ celulose $(\mathrm{m} / \mathrm{m}) /$ PS em comparação ao PS reciclado que foi de 2,48 , confirmando a interação entre a matriz de poliestireno e a fibra celulósica + lignina residual. As avaliações da energia do compósito estão relacionadas ao pico de tan $\delta$ [25]. Quanto mais forte a interação fibra/ matriz menor é a dissipação de energia, que resulta em menor altura do pico tan $\delta$, já que a liberação de energia nos compósitos ocorre via interface [26]. Uma vez que o valor de $\tan \delta$ indica o grau de amortecimento mecânico, quanto mais flexível o sistema, maior o grau de amortecimento [28].

Tabela 1: Temperatura de transição vítrea $\left(\mathrm{T}_{\mathrm{g}}\right)$, módulo de armazenamento ( $\left.\mathrm{E}^{\prime}\right)$, módulo de perda (E") e amortecimento (Tan $\delta$ ) do PS reciclado e dos compósitos.

\begin{tabular}{l|c|c|c|c}
\hline \multicolumn{1}{c|}{ Materiais } & $\begin{array}{c}\mathbf{E}^{\prime} \mathbf{7 0}{ }^{\circ} \mathbf{C} \\
(\mathbf{G P a})\end{array}$ & $\begin{array}{c}\mathbf{E}^{\prime \prime} \mathbf{9 5}{ }^{\circ} \mathbf{C} \\
(\mathbf{M P a})\end{array}$ & $\begin{array}{c}\text { Tan } \boldsymbol{\delta} \\
(\text { pico })\end{array}$ & $\begin{array}{c}\mathbf{T}_{\mathbf{g}} \\
\left({ }^{\circ} \mathbf{C}\right)\end{array}$ \\
\hline PS reciclado & 1947,3 & 455,5 & 2,48 & 105,6 \\
\hline Compósito de celulose $\mathbf{1 0 \%}(\mathbf{m} / \mathbf{m}) /$ PS & 2574,9 & 496,7 & 1,48 & 105,5 \\
\hline Compósito de celulose $\mathbf{2 0 \%}(\mathbf{m} / \mathbf{m}) /$ PS & 2851,0 & 497,6 & 1,18 & 103,5 \\
\hline
\end{tabular}

Em termos de valores a $\mathrm{T}_{\mathrm{g}}$ para os materiais a mudança não foi notável, $\mathrm{T}_{\mathrm{g}}$ igual a $105,6^{\circ} \mathrm{C}$ para o PS e $103,5^{\circ} \mathrm{C}$ para o compósito reforçado com $20 \%(\mathrm{~m} / \mathrm{m})$ de fibras.

\subsubsection{Temperatura de deflexão térmica (HDT)}

A HDT representa a temperatura máxima que um material submetido a um determinado esforço permanece sem sofrer deformação [29]. Segundo dados reportados na literatura, fatores como: quantidade de reforço, razão de aspecto das partículas e grau de dispersão da carga na matriz polimérica, interação entre fibra/ matriz podem promover aumentos de HDT [30]. 
O ensaio de temperatura de deflexão térmica é de fundamental importância em compósitos, pois a partir dele determina-se a temperatura máxima de trabalho para um dado material, acima do qual o mesmo possivelmente não conseguirá desempenhar as suas funções para a qual foi projetado. Este ensaio é frequentemente realizado na indústria automotiva, onde peças em contato com o motor podem atingir uma temperatura acima de $100^{\circ} \mathrm{C}$ e o interior de um veículo pode chegar a atingir temperaturas próximas dos $60^{\circ} \mathrm{C}$ [31]. Verifica-se por meio da Tabela 2, que no ensaio de HDT, o compósito de celulose $10 \%(\mathrm{~m} / \mathrm{m}) /$ PS apresentou uma temperatura de deflexão 5,6\% menor que o compósito de celulose $20 \%(\mathrm{~m} / \mathrm{m}) / \mathrm{PS}$.

Tabela 2: Temperatura de deflexão térmica do polímero e dos compósitos.

\begin{tabular}{c|c|c}
\hline PS reciclado & $\begin{array}{c}\text { Compósito de celulose } \\
\mathbf{1 0 \%}(\mathbf{m} / \mathbf{m}) / \mathbf{P S}\end{array}$ & $\begin{array}{c}\text { Compósito de celulose } \\
\mathbf{2 0 \%}(\mathbf{m} / \mathbf{m}) / \mathbf{P S}\end{array}$ \\
\hline $75,47 \pm 1,76$ & $79,7 \pm \pm 0,14$ & $83,93 \pm 0,06$ \\
\hline
\end{tabular}

Pode ser observado que a presença da fibra de celulose/ lignina produz um aumento no valor da temperatura de deflexão para todos os compósitos. Algumas propriedades são maximizadas com a adição de fibras, tais como as propriedades térmicas [32].

BORSOI et al., [33] reportaram na literatura que a adição de fibras naturais em polímeros aumenta a rigidez do material, como pode ser observado pela análise do tan $\delta$, ocasionando um aumento da temperatura de deflexão térmica. Para o compósito com $20 \%$ de fibra, em comparação ao PS reciclado, o aumento da temperatura de deflexão térmica foi de aproximadamente $9^{\circ} \mathrm{C}$.

Com adição das fibras de celulose e o efeito compatibilizante da lignina residual, esses restringem a movimentação das cadeias carbônicas da matriz polimérica, diminuindo também coeficiente de expansão térmica, o que proporciona maior estabilidade dimensional no material [34]. Para alguns polímeros amorfo como o poliestireno as fibras podem atuar como pontos de concentradores de tensão, uma vez que a interface entre fibra e a matriz amorfa não apresenta excelente adesão [35].

Em estudo recente MAZZINI [31] verificou que compósito polimérico com fibras naturais tem tendência a diminuir a mobilidade dos segmentos de cadeia da estrutura polimérica, e isso resulta em aumento da rigidez do material, porém com diminuição da sua ductilidade. Em relação à resistência térmica, a incorporação das fibras naturais na matriz polimérica resultou em um aumento progressivo no valor da temperatura de deflexão térmica. Isso ocorre devido às fibras aumentarem a resistência à flexão da cadeia polimérica, inclusive em temperaturas elevadas. Uma vez que as fibras restringem a movimentação dos segmentos de cadeias da matriz polimérica, esse efeito, somado à resistência mecânica da fibra, facilita o aumento da resistência final do compósito em temperaturas altas.

\section{CONCLUSÕES}

A polpação das fibras de bagaço de cana-de-açúcar foi um método eficaz para obtenção de fibra de celulose, resultando em um razoável rendimento além de uma quantidade de lignina residual. A lignina residual pode ter atuado como agente compatibilizante possibilitando uma maior interação entre a fibra e a matriz. Essas interações influenciaram as propriedades térmicas dos compósitos em relação ao PS reciclado.

As análises de TGA e DSC mostraram que a estabilidade térmica dos compósitos reforçados com as fibras celulósicas foi reduzida em relação ao PS reciclado, inclusive com o aumento do teor de fibras. Já por meio do DMA percebeu-se um aumento do módulo de armazenamento e redução da altura do pico tan $\delta$ com a incorporação das fibras com a lignina residual. Uma vez que as fibras de celulose/ lignina restringem a movimentação das cadeias do PS, esse efeito somado à resistência mecânica da fibra facilita o aumento da resistência final do compósito em temperaturas mais elevadas.

Verificou-se que a adição de fibra de celulose foi suficiente para promover boa adesão interfacial entre a lignina residual da fibra e a matriz do poliestireno, porém os resultados com a adição de $20 \%$ de celulose foram mais significativos em relação aos ganhos das dinâmico-mecânicas.

Os resultados do ensaio de HDT demonstraram que a presença da fibra de celulose e a lignina produziram um aumento no valor da temperatura de deflexão para todos os compósitos. Portanto, conclui-se que a utilização de EPS como matriz em compósitos reforçados com fibras naturais é viável, permitindo sugerir ao mercado de reciclagem, uma excelente alternativa para o aproveitamento deste resíduo.

\section{AGRADECIMENTOS}

Os autores agradecem o apoio financeiro da Capes, UnB, UCS, UFRGS, FAP-DF e CNPq. 


\section{BIBLIOGRAFIA}

[1] ABDELMOULEHA, M., BOUFIA, S., BELGACEMB, M. N., et al., "Modification of cellulosic fibres with functionalised silanes: development of surfasse properties", International Journal of Adhesion \& Adhesives, v. 24, n. 1, pp. 43-54, Jul. 2004.

[2] GUTIÉRREZ, J. C. H., RUBIO, J. C. C., FARIA, P. E., "Usinabilidade de materiais compósitos poliméricos para aplicação automotivas”, Polímeros: Ciência e Tecnologia, v. 24, n. 6, pp. 711-719, Mai. 2014.

[3] RODRIGUES, J., SOUZA, J. A., FUJIYAMA, R., "Compósitos poliméricos reforçados com fibras naturais da Amazônia fabricados por infusão", Matéria (Rio de Janeiro), v. 20, n. 4, pp. 946-960, dez. 2015.

[4] SILVA, R., HARAGUCHI, S. K., MUNIZ, E. C., et al., "Aplicações de fibras lignocelulósicas na química de polímeros e em compósitos”, Química Nova, v. 32, n. 3, pp. 661-671, Mar. 2009.

[5] LUZ, S. M., GONÇALVES, A. R., DEL'ARCO JUNIOR, A. P., "Microestrutura e propriedades mecânicas de compósitos de polipropileno reforçado com celulose de bagaço e palha de cana". Matéria (rio de Janeiro), v. 11, n. 2, p.101-110, Mai. 2006.

[6] ISENMANN, A., Química a partir de Recursos Renováveis, 3 ed., São Paulo, Edição do Autor, 2016.

[7] JESUS, L. C. C., Obtenção e caracterização de compósitos de poliestireno expandido pós-consumo reforçados com celulose de bagaço de cana-de-açúcar, Dissertação de M.Sc., UnB, Brasília, DF, Brasil, 2014.

[8] NONAKA, H., YAMAMOTO, R., KATSUZAKI, H., et al., "Suggested production of a guaiacyl benzofuran derivative from softwood via lignocresol", BioResouces, v. 11, n. 3, pp. 6932-6939, Jul. 2016.

[9] Editoria, PORTAL DA CONSTRUÇÃO, https://www.oportaldaconstrucao.com, Acessado em fevereiro de 2018.

[10] BURADOWSKI, L., REZENDE, M.C., "Modificação da rugosidade de fibras de carbono por método químico para aplicação em compósitos poliméricos", Polímeros: Ciência e Tecnologia, v. 11, n. 2, pp. 51-57, 2001.

[11] CHAGAS, F. H. C., BERRETTA-HURTADO, A. L., GOUVÊA, C. A. K., "Logística Reversa: Destinação dos Resíduos de Poliestireno Expandido (Isopor ${ }^{\circledR}$ ) Pós-Consumo de uma Indústria Catarinense", In: $3^{r d}$ International Workshop Advances in cleaner production, São Paulo, Brasil, 18-20 March 2011.

[12] FINK, H. P., FARUK, M. S. O., "Biocomposites reinforced with natural fibers: 2000-2010", Progress in Polymer Science, v. 37, n. 11, pp. 1552-1596, 2012.

[13] NOHARA, L. B., KAWAMOTO, A. M., TAKAHASHI, M. F. K., et al., "Síntese de um poli (ácido âmico) para aplicação como interfase em compósitos termoplásticos de alto desempenho". Polímeros: Ciência e Tecnologia, v. 14, n. 2, pp. 122-128, 2004.

[14] BORSOI, C., SCIENZA, L. C., ZATTERA, A. J., "Characterization of Composites Based on Recycled Expanded Polystyrene Reinforced with Curaua Fibers", Journal of Applied Polymer Science, v. 128, n. 1, pp. 653-659, Jul. 2013.

[15] Editoria, CARASCHI, J. C., ROSA, R. R., SANTIAGO, L. F. F., VENTORIM, G., http://www.eucalyptus.com.br/icep03/02_Caraschi_Rosa_Santiago_Ventorim.pdf. Acessado em fevereiro de 2018.

[16] CAPIM, S. L., SANTANA, S. R., OLIVEIRA, B. G., et al., "Revisiting the origin of the preferential $\pi$ $\pi$ stacking conformation of the (+)-8-phenylmenthyl acrylate", Journal Of The Brazilian Chemical Society, v. 21, n. 9, pp. 1718-1726, 2010.

[17] NETTO, A. V. G., FREM, R. C. G., MAURO, A. E., "A química supramolecular de complexos pirazólicos", Química Nova, v. 31, n. 5, pp.1208-1217, 2008.

[18] ROMANZINI, D., LAVORATTI, A., ORNAGHI Jr., H. L., et al., "Preparation and characterization of ramie-glass fiber reinforced polymer matrix hybrid composites", Materials and Design, v. 15, n. 3, pp.415420, 2012.

[19] LUZ, S. M., GONÇALVES, A. R., DEL'ARCO Jr, A. P., et al., "Thermal properties of polypropylene composites reinforced with different vegetable fiber" Advanced Materials Research, 123-125, pp. 1199-1202, 2010.

[20] PETTERSEN, R. C., The chemical composition of wood, 1 ed., Washington, R.(ed), 1984.

[21] BOTAN, R., NOGUEIRA, T. R., LONA, L. M. F., "Síntese e caracterização de nanocompósitos de poliestireno/hidroxissal lamelar", Polímeros: Ciência e Tecnologia, v. 37, n. 01, pp. 18-21, 2014.

[22] FENGEL, D., WEGENER, G., Wood: Chemistry, Ultrastructures andreactions, 1 ed., Germany: Water de Gruyter, 2003.

[23] BORSOI, C., BERWIG., K., SCIENZAC, L. C., et al., "Behavior in simulated soil of recycled expanded 
polystyrene/waste cotton composites", Materials Research, v. 17, n. 1, 2014.

[24] ROUMELI, R., TERZOPOULOU, Z., PAVLIDOU, E., et al., "Effect of maleic anhydride on the mechanical and thermal properties of hemp/high-density polyethylene green composites" Journal of Thermal Analysis and Calorimetry, v. 121, n. 1, pp. 93-105, 2015.

[25] CANEVAROLO, Jr. S. V., Técnica de caracterização de polímeros, 1 ed., São Paulo, Artliber, 2007.

[26] POLETTO, M., DETTENBORN. J., ZATTERA, A. J., et al., "Avaliação das propriedades mecânicas de compósitos de Poliestireno expandido pós-consumo e serragem de Pinus elliottii" Revista Iberoamericana de polímeros. v. 11, n. 1, pp. 169- 177, 2010.

[27] ARAÚJO, S. S., CAVALCANTI, N. F., DUARTE, I. S., et al., "Desenvolvimento de compósitos pp/sisal extrudados: estudo do efeito do tratamento alcalino das fibras nas propriedades mecânicas e termomecânicas", In: Resumo do VI Congresso nacional de engenharia mecânica, Campina Grande, Paraíba, Brasil, 18-21 Agosto 2010.

[28] IDICULA, M., MALHOTRA, S.K., KURUVILLA, J., et al., "Dynamic mechanical analysis of randomly oriented intimately mixed short banana/sisal hybrid fibre reinforced polyester composites" Composites Science and Technology, v.65, n. 7, pp. 1077-1087, 2005.

[29] DILSIZ, N., WIGHTMAN, J.P., "Effect of acid-base properties of unsized and sized carbono fibers on fiber/epoxy matrix adhesion" Colloids and Surfaces (2000), v. 164, n. 2, pp. 325-336, 2000.

[30] MURPHY, J., The Reinforced Plastics Handbook, 1 ed., New York, Elsevier Advanced Technology, 1994.

[31] MAZZINI, F. P., CALVÃO, P. S., "Obtenção e caracterização do compósito de poli(ácido láctico) (PLA) com fibra de bagaço de cana-de-açucar", In: Resumo do $12^{\circ}$ Congresso Brasileiro de Polímeros, Florianapólis, Brasil, 22-26 Setembro 2013.

[32] MIGUEL, J. J. P., Estudo comparativo das propriedades térmicas e mecânicas do polipropileno reforçado com óxido de zinco, carbonato de cálcio e talco, Dissertação de M.Sc., CCT/FIEB, Salvador, BA, Brasil, 2010.

[33] BORSOI. C., CAVINATO, C., SCIENZA, L. C., et al., "Processing of recycled expanded polystyrene and waste newsprint fibers composites Proceedings of the Polymer Processing", In: Society 29th Annual Meeting - PPS-29, Nuremberg, Germany, 15-19 July 2013.

[34] BRYDSON, J. A., Plastics Materials, 6 ed., London, Butterworth-Heinemann Ltda, 1995.

[35] SILVA. C.G., Bagaço de cana de açúcar como reforço de matrizes termorrígidas baseadas em macromoléculas de lignina, Tese de D.Sc., Instituto de Química/ USP. São Paulo, SP, Brasil, 2008.

\section{ORCID}

Luiz Carlos Correia de Jesus

Sandra Maria da Luz

Rosineide Miranda Leão

Sandro Campos Amico

Ademir Jose Zattera https://orcid.org/0000-0003-1079-4003

http://orcid.org/0000-0002-2223-0021

https://orcid.org/0000-0002-4218-3445

https://orcid.org/0000-0003-4873-2238

https://orcid.org/0000-0002-2198-4323 